Becoming a steward of data science

Rochelle E. Tractenberg

Reprint requests:

Rochelle Tractenberg

Neurology Department, Building D, Suite 207

Georgetown University Medical Center

4000 Reservoir Rd. NW

Washington, DC 20057 USA

rochelle.tractenberg@gmail.com

KEYWORDS: Stewardship; Mastery Rubric for Stewardship; Data Science; ethical practice. 


\begin{abstract}
This article introduces the concept of the steward: the individual to whom the public, and other practitioners, can entrust the integrity of their field. The concept will be defined, particularly with respect to what about stewardship can be demonstrated by the practitioner so that others including other stewards - can recognize this professional identity. Stewardship is an important aspect of professionalism, and although data science is a very new profession, its growth in terms of the number of practitioners should also include growth in the commitment to integrity in practice. Although an undergraduate program may seem early to begin understanding what this commitment means, and how to generate evidence of that commitment for yourself, those with a strong understanding of stewardship and how to recognize it will be better able to select jobs in contexts where this commitment to integrity is nurtured and valued. Learning about stewardship engages students in taking responsibility for their role in the profession, and so taking responsibility for the profession and the professional community. Once the construct is understood, learners can focus on the nature of the evidence they can compile - as well as the types of activities that can generate that kind of evidence- and on why this is meaningful over their career.
\end{abstract}




\section{What is stewardship?}

"Upon entry into practice, all professionals assume at least a tacit responsibility for the quality and integrity of their own work and that of colleagues. They also take on a responsibility to the larger public for the standards of practice associated with the profession". (Golde \& Walker 2006: 10)

A steward is defined as one to whom "we can entrust the vigor, quality, and integrity of the field" (Golde \& Walker 2006: p. 5). Note that "integrity" is a key factor of stewardship, but the steward is entrusted to preserve and promote the integrity of the field. To do so, or to be entrusted to do so, implicitly entails personal and professional integrity as well. We would entrust an ethical practitioner to have this personal and professional integrity; so in this discussion we consider the "ethical" practitioner to be stewardly and to have personal and professional integrity. These words (ethical; stewardly; with integrity) are used somewhat interchangeably, but they differ in terms of what is observable. This article discusses stewardship and how it can be/be made to be observable; elsewhere (Tractenberg, 2019) I discuss ethical reasoning as a way of rendering "ethical" behaviors more observable. Being stewardly involves both ethical practice and professional integrity; if you are stewardly and practice data science ethically, these serve to make your professional integrity observable. Together, stewardship and ethical practice promote the integrity of the field.

Rios, Golde \& Tractenberg (2019) refined the construct of stewardship from its origins as specific to people who earn their PhDs, so that it could be applied to any person practicing in any field. As long as the practitioner seeks to become one to whom "we can entrust the vigor, quality, and integrity of the field", irrespective of the level of schooling they complete (or have yet completed), this construct can apply to them. In fact, the original authors also envisioned the applicability of the stewardship construct more widely, stating that, "Upon entry into practice, all professionals assume at least a tacit responsibility for the quality and integrity of their own work and that of colleagues. They also take on a responsibility to the larger public for the standards of practice associated with the profession". (Golde \& Walker, 2006: p 10). It is important to recognize that the profession currently labeled "data scientist" has many - highly varied definitions. Not only that, but people can move into a job with that, or a similar, title from a highly diverse range of training and education. In a 2015 article discussing ethics and "big data", Tractenberg et al pointed out that this variability in how people come to be prepared to practice in the data science domain complicates the preparation for professional practice: "( $\mathrm{t}$ )his diversity presents a significant problem: no single discipline exists to govern, or even to create norms around ethical practices in, Big Data use or research." (Tractenberg et al. 2015, p. 1486) Thus, the concept of stewardship is an important one: Rios et al. argue that anyone can become an individual to whom the integrity of a field can be entrusted, as long as they develop the particular range of knowledge (K), skills (S), and abilities (A) associated with the steward.

To facilitate the development of these KSAs, Rios et al. created a curriculum tool called a Mastery Rubric that is specific to the KSAs of stewardship. "A Mastery Rubric is a tool for curriculum development and evaluation that articulates a curriculum's intended outcomes and integrates a developmental trajectory that moves learners from novice to more expert performance within an evidence-centered design framework." (Rios et al. p. 9). The Mastery 
Rubric (MR) as a tool is fully discussed in Tractenberg (2017). What is important for our discussion is that the MR for stewardship (MR-S) describes both eight distinct, but interrelated KSAs that together are demonstrated by those who are, or who seek to become, stewards, together with performance level descriptors that can generally guide the creation of evidence that each KSA can be achieved at each of four levels. The eight KSAs that define stewardly behavior are:

1. Requisite knowledge/situational awareness (which includes knowledge of professional practice standards)

2. Create and/or generate new methods/new knowledge in/for the profession or discipline

3. Critically evaluate extant and emerging ideas in/for the profession or discipline

4. Conserve ideas in/for the profession or discipline (or not, if deemed rejectable \& nonconservation is justified)

5. Responsibly write (disciplinary scholarship)

6. Responsibly teach/mentor/model (formally and informally)

7. Responsibly apply the knowledge and principles of the discipline

8. Responsibly communicate (outside of scholarly venues)

The four stages at which each of these is demonstrated are:

Novice: The novice is just beginning to engage with the discipline.

Apprentice: The apprentice is actively engaged in study of the profession or discipline, who is learning that "tacit responsibility for the quality and integrity of their own work and that of colleagues", and the "responsibility to the larger public for the standards of practice associated with the profession" that Golde \& Walker (2006) asserted are essential to any professional.

Journeyman: The journeyman is an independent practitioner who is a steward of the discipline.

Master: The Master steward is recognized by evidence and consensus as one who teaches effectively.

Rios et al. (2019), p. 16-17

If this role appeals to you, you can develop the stewardly mindset and commit to learning and following (modeling, and promoting) your profession's practice guidelines. Elsewhere (Tractenberg, 2019) I discuss how to do this with the guidelines from the American Statistical Association (ASA) and the Association for Computing Machinery (ACM), both of which should be influential for anyone who handles and works with data - at any point along the stream from collection to analysis to interpretation. Here we focus on stewardship and how data science and data scientists can benefit from this construct.

\section{Why is stewardship relevant?}

Consensus is building: Responsibilities accrue when data are "ingested" and analyzed. Part of this consensus comes from the fact that data breaches are increasing at a worrying rate (Techworld, 12 March 2019). In their "year in review" of artificial intelligence, The AI Now Institute created an astonishing timeline: 


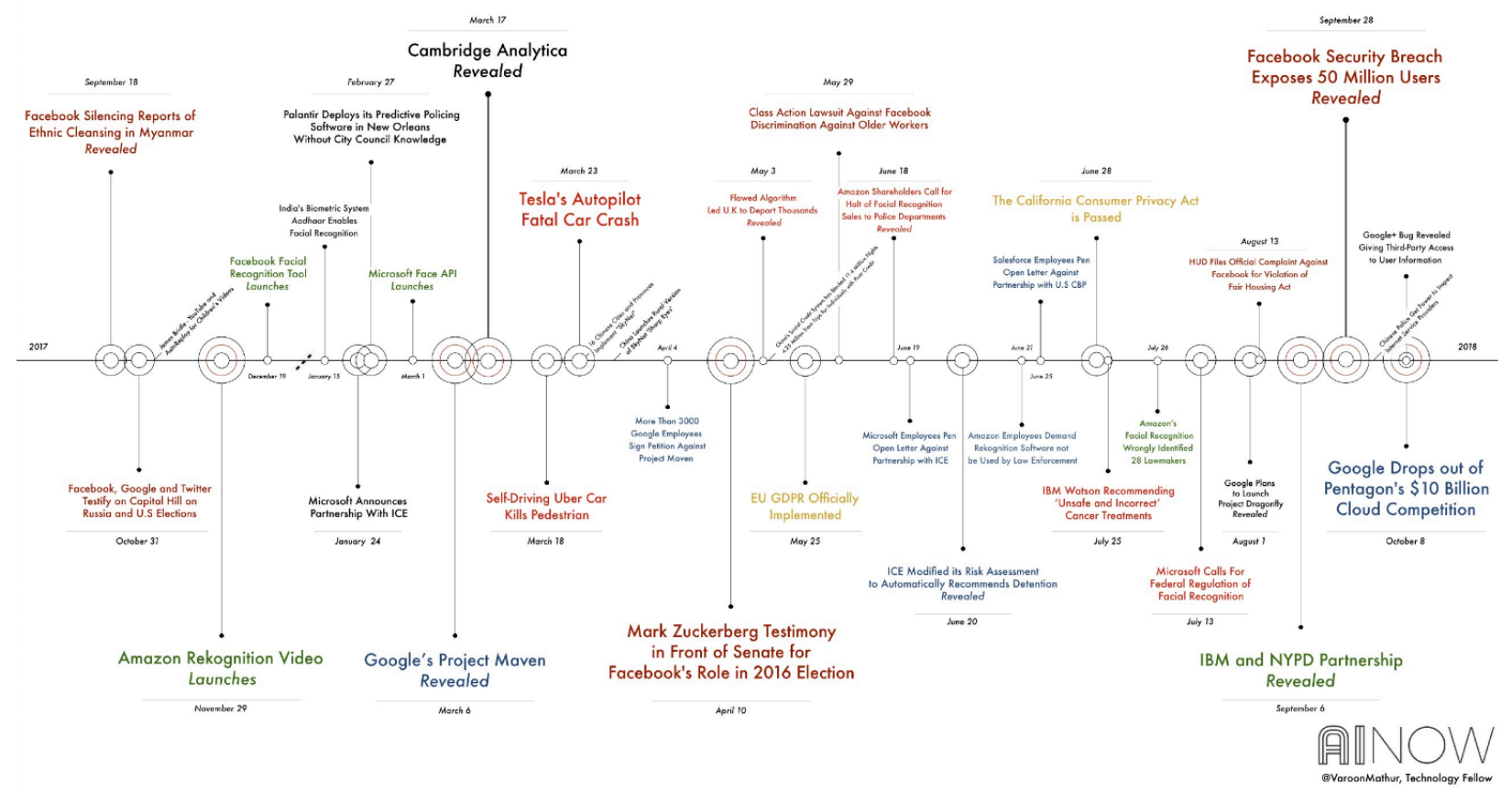

Image attributed to Varoon Mathur; captured 25 March 2019 from https://medium.com/@AINowInstitute/ai-in-2018-a-year-in-review-8b161ead2b4e

Importantly for this figure, only "news events" are presented, and some of those events include testimony and other activities that did not involve data science directly. What the figure demonstrates includes the following.

A. "ethical problems" include both frankly illegal activity, such as violating privacy and other laws to illegally obtain data; and other activities that were not intentional but still raise ethical challenges, such as the deaths caused by driverless cars.

B. Violations that were not (or have not yet been) reported would not have been included in the figure. If you explore any of the cases in the figure you will undoubtedly find that the report of the case followed, sometimes by months, the events in question (see Wong 2019). So this figure represents only a fraction of the actual ethical violations that happened just in this timeframe.

C. The Cambridge Analytica scandal, revealed on 17 March 2018 according to the figure (see https://en.wikipedia.org/wiki/Facebook\%E2\%80\%93Cambridge_Analytica_data_scandal for details), involved the illegal access of personal data from Facebook users. According to reports, a data scientist at Cambridge University created a program that either did, or was modified to do, the illegal harvesting of data from across Facebook (instead of just collecting what was supposed to be collected from only those who consented to have their data collected). This is only one example of the potential harms that can accrue to the public even if the data scientist did not intend for that to happen.

D. While Cambridge Analytica was able to steal data using the product from one data scientist who did not work there, other data scientists needed to engage in the work to utilize the data that was collected. We know for certain that none of the professionals who were hired or paid to engage in any of these activities had been trained to be stewards, because stewardship is not (yet) a widely taught or practiced construct. Awareness of the 
potential for unethical behavior by data scientists has led to the profession "data science" becoming a target requiring ethical guidelines of some kind (e.g., Simonite 2018; Loukides et al. 2018). Public trust in this discipline was harmed by each of these events, and legislation in the United States and European Union was created specifically to limit the potential for data science to engage in harmful behaviors.

There is no real consensus, though, on how to respond to what is obviously a growing problem: data science being used in harmful ways. Part of the motivation for this article is raising awareness of responsibilities to the profession and to those served or affected by the profession. Training new practitioners and the people with whom they work to "do the right thing" needs attention; hopefully this article will convince each reader that a stewardly mindset is a worthwhile mindset to begin to cultivate and to as you move forward in your training and career. For example, if faced with the decision of those hired or asked to specifically modify or deploy the tool that led to illegal access of the Facebook data from millions of users, the data scientist could have simply used the KSAs of stewardship for guidance.

Table 1. Do the stewardship KSAs provide any guidance to a data scientist with a questionable request?

\begin{tabular}{|l|l|}
\hline Stewardship KSA: & Should I fulfill this request? \\
\hline $\begin{array}{l}\text { Requisite } \\
\text { knowledge/situational } \\
\text { awareness (which includes } \\
\text { knowledge of professional } \\
\text { practice standards) }\end{array}$ & $\begin{array}{l}\text { Check professional practice standards to see if modifying } \\
\text { someone else's work is problematic. Professional guidelines } \\
\text { also stipulate uniformly that harms should be limited - not } \\
\text { created - by ethical professional activities }\end{array}$ \\
\hline $\begin{array}{l}\text { Create and/or generate new } \\
\text { methods/new knowledge } \\
\text { in/for the profession or } \\
\text { discipline }\end{array}$ & $\begin{array}{l}\text { If I do this, I will create new knowledge (adapting the } \\
\text { existing program) that will decrement trust in this profession. }\end{array}$ \\
\hline $\begin{array}{l}\text { Critically evaluate extant and } \\
\text { emerging ideas in/for the } \\
\text { profession or discipline }\end{array}$ & $\begin{array}{l}\text { Adapting this program could make this profession the target } \\
\text { of legal action. }\end{array}$ \\
\hline $\begin{array}{l}\text { Conserve ideas in/for the } \\
\text { profession or discipline (or } \\
\text { not, if deemed rejectable \& } \\
\text { non-conservation is justified) }\end{array}$ & $\begin{array}{l}\text { This program may need refinements (or warning labels) if it } \\
\text { can easily be hacked to result in harms. }\end{array}$ \\
\hline $\begin{array}{l}\text { Responsibly write } \\
\text { (disciplinary scholarship) }\end{array}$ & $\begin{array}{l}\text { Fully documenting this program (and/or my adaptations of } \\
\text { this program) could help warn users or potential targets of its } \\
\text { use. }\end{array}$ \\
\hline $\begin{array}{l}\text { Responsibly } \\
\text { teach/mentor/model (formally } \\
\text { and informally) }\end{array}$ & $\begin{array}{l}\text { Fulfilling this request could signal to the requestor, or to } \\
\text { others, that creating harms is an OK thing to do for any data } \\
\text { scientist. }\end{array}$ \\
\hline $\begin{array}{l}\text { Responsibly apply the } \\
\text { knowledge and principles of } \\
\text { the discipline }\end{array}$ & $\begin{array}{l}\text { Creating something that leads to harms is not a responsible } \\
\text { application of my data science knowledge. }\end{array}$ \\
\hline
\end{tabular}




\begin{tabular}{|l|l|}
\hline $\begin{array}{l}\text { Responsibly communicate } \\
\text { (outside of scholarly venues) }\end{array}$ & $\begin{array}{l}\text { Telling the requestor or user that the program (or my } \\
\text { modifications of it) could lead to harms is responsible } \\
\text { communication; failing to warn the public or the requestor is } \\
\text { irresponsible communication. }\end{array}$ \\
\hline
\end{tabular}

Table 1 suggests that the simple consideration of the KSAs of stewardship could have led to different decisions by data scientists, possibly also leading away from the borderlineillegal/clearly unethical activities by the Cambridge Analytica team. While those who intend to do harm will never be swayed by arguments that "doing harm is not stewardly" (nor will they be dissuaded from doing harm by the fact that it is illegal), if more data scientists raised objections, refused to participate, or notified authorities than agreed to participate in such practices, the harms could possibly be mitigated.

This example is extreme, and there are many decisions that happen at virtually every stage in the practice of data science as a profession. That is why it is so important for us to promote the integration of a stewardly mindset early in professional development, and for every practitioner. The demand for data scientists will not diminish because of these breaches, even when laws are passed to prevent them and to constrain data science and its applications; even as data science violations (whether illegal or simply unethical yet legal) have become increasingly common, more people are seeking to be trained in this field because the job is in high demand. However, at some point, negative views by the public of the profession may lead to less interest in -and opportunities for - learning to do the job well and carefully.

You may have heard the quote, "Be the change you wish to see in the world"; this is typically misattributed to the leader of the peaceful independence movement in India starting in 1915 (https://en.wikipedia.org/wiki/Mahatma_Gandhi\#Biography), Mohandas Ghandi. What he actually said was: "If we could change ourselves, the tendencies in the world would also change. As a man changes his own nature, so does the attitude of the world change towards him. ... We need not wait to see what others do." MK Ghandi, 1913

More recently, and specifically relating to data science, Loukides et al. (2018) suggest that "Cultural change may take time, but it will happen-if we are that change. That's what it means to do good data science." Irrespective of whether your role is that of a data wrangler, data scientist, statistician, or person who occasionally uses data - obtained, managed, analyzed by others - to make decisions, a stewardly approach will tend to limit the harms that may result from those decisions. Changing yourself, as Ghandi said, is the first step towards changing the culture to one that values and promotes stewardship.

\section{How do I become a Steward?}

The first step in becoming a steward is to accept the responsibility of being a steward: Accept it, model it, and promote it. For some practitioners, there is a 'fear of missing out' or an unwillingness to engage with stewardship when no one else is doing that. This actually drives a lot of possibly surprising behavior - data scientists may accept assignments or carry out tasks they're given because if they do not, the asker/assigner will simply hire someone else who will 
do that task. This is one of the ongoing challenges of dissemination and education - and the development of professional identity - to encourage all practitioners to say NO to unethical requests, or requests to engage in behaviour that is not stewardly or not consistent with existing professional guidelines. It is not that the people accepting the tasks are not ethical, or that they are not competent, but rather that they believe that there will be someone (possibly someone who IS unethical, or incompetent, or both) who will accept the job. Simply considering decisions that you make using the stewardship KSAs can help you as well as the profession: consider how much more trust people would have in the profession of data science if everyone knew that data scientists were trained to consider their stewardly obligations.

\section{The visible steward}

Stewardship is a mindset, but it ends up having the potential to be very visible. Rios et al. (2019) describe both all the KSAs of stewardship and also, how performance of these KSAs can (and should) change over time as the steward evolves. Important for your understanding of the observable changes in KSA performance is a brief discussion of the complexity of your thinking and reasoning skills. This complexity is summarized in Bloom's Taxonomy of Cognitive Behaviors (Bloom et al. 1956). The taxonomy is a six-level hierarchy of cognitive skills or functioning. The fact that the taxonomy is a hierarchy is important for our discussion, because it means that earlier or lower levels need to be developed before the next levels can be initiated. These six levels are:

1. Remember/Reiterate, where performance is based on recognition of already-seen example(s);

2. Understand/Summarize, where performance utilizes information that has already known/given;

3. Apply/Illustrate, where performance extrapolates from seen examples to new ones by applying rules;

4. Analyze/Predict, where performance requires analysis and prediction, using rules.

The majority of tests in formal education require Bloom's levels 1-4. However, it is the higher levels of cognitive abilities that we use in our daily lives and in the workplace - and these are the most difficult abilities to cultivate:

5. Create/ Synthesize, where performance yields something innovative and novel. The creation, description, and justification of something new -whether or not it is derived from existing things/ideas - is highly complex and abstract.

6. Evaluate/Compare/Judge, the most complex type of thinking because it does not involve rules but does require consideration and prioritization of abstract features of material. Bloom's level 6 is the most complex cognitive level because performance involves applying guidelines -if they exist, and can involve subtle differences arising from comparison or evaluation of abstract, theoretical or otherwise not-rule-based decisions, ideas or materials.

Methods for demonstration that you are growing in your commitment and abilities to act in a stewardly way include professional portfolios, which can show a commitment by those in early stages of developing a stewardly mindset - or achievement by those in later stages of the stewardly mindset development process. In fact, evidence of stewardship, and of the development of this identity, can be derived from many activities one already does - from coursework or your individual, self-directed study; or from engagement in your job, your 
profession, your context. Sharing this evidence can promote the culture change that is needed: if you take the time to create and cultivate the evidence, it transmits your value for stewardship and observable evidence of its existence. When you share that evidence, you demonstrate that beyond a transcript - you can show both the level at which you perform each KSA and also, the types of opportunities you would like to have in order to continue your development.

\section{Creating and sharing evidence, stage by stage}

The novice is just beginning to engage with the discipline. This individual is just beginning to learn about each KSA, so the work they do is usually at Bloom's levels 1-2 of cognitive complexity 1-2 (understand, summarize). The novice steward does not yet recognize that, or act as if, failures to act in a stewardly manner have ramifications beyond themselves. Thus, to ensure that you move out of the novice stage, it is essential to begin to consider what it means to you, to your profession, and to the public trust in your profession when you do not act in a stewardly manner. Making your commitment to becoming - and then being - a steward visible is how you begin to move out of the novice stage - not simply to get to the next level, but to engage with the idea of stewardship of data science, and recognize your responsibility for performing - whatever you do - in a stewardly way. It is important to point out that an experienced data scientist who does not recognize that, or act as if, failures to act in a stewardly manner have ramifications beyond themselves is not even a novice steward, in spite of their years of experience. These stages do not depend on time-in-position, they reflect, in observable ways, how you do your job (ethically vs not) and demonstrate your responsibility for the integrity of the profession or field.

Whether learning in an academic setting or even on the job, the novice steward is prepared to reason with facts and pre-defined problems, using legal (rules) and the most concrete professional practice standards. Apprentices are in the process of developing an awareness of the dimensions of stewardship and professionalism, and also of their own development or place in the continuum. This is and requires a more abstract level of thinking about what are fairly abstract concepts (stewardship, professionalism) and therefore, require the practitioner to bring more advanced thinking to bear. That is, the novice tends to perform stewardly KSAs at Bloom's levels 1-2 (understand, summarize), moving towards developing levels 3 (apply) and 4 (analyze/predict) while the apprentice is more firmly performing at levels 3-5. The apprentice stage is likely to be a long one, because the formation of professional identity and the opportunity to develop and demonstrate achievement at the apprentice steward level may take time. While you may be eager to demonstrate that you are in fact fully committed to, and engaged in establishing, the "tacit responsibility for the quality and integrity of their own work and that of colleagues", and the "responsibility to the larger public for the standards of practice associated with the profession" that Golde \& Walker (2006) describe, some level of real-world experience is required in order to be recognized as an individual to whom the vigor and integrity of the field will be entrustable (once the journeyman level is achieved).

The journeyman is a steward of the discipline, performing all of the KSAs with understanding, analysis, and synthesis of their experience with their knowledge, functioning at the highest Bloom's levels in their working life. This individual is recognizable as someone to whom the integrity of the field can be entrusted; someone whose integrity, and whose commitment to their field or profession, is observable. Journeyman level performance of each 
KSA is reflective, and includes analysis and synthesis of their experience with their knowledge (Bloom's 4-6).

To focus our discussion of evidence on the formation of the steward of data science, we will explore just the first three levels of the developmental trajectory - to initiate your evolution from a novice steward to the journeyman, the person who is stewardly in practice.

Table 2. General performance descriptors from The Mastery Rubric for Stewardship. Adapted with permission of the Authors from Rios et al. (2019).

\begin{tabular}{|c|c|c|c|}
\hline $\begin{array}{r}\text { Developmental } \\
\text { stage } \\
\text { performance } \\
\text { level of } \\
\text { stewardship }\end{array}$ & Novice & Apprentice & Journeyman \\
\hline $\begin{array}{l}\text { General } \\
\text { descriptor of } \\
\text { performance: }\end{array}$ & $\begin{array}{l}\text { Has interest but } \\
\text { limited experience in } \\
\text { the discipline or } \\
\text { profession, but is } \\
\text { being introduced to } \\
\text { the ideas and } \\
\text { commitments that } \\
\text { the Apprentice will } \\
\text { build upon. } \\
\text { Is discovering the } \\
\text { importance of } \\
\text { disciplinary and } \\
\text { professional } \\
\text { stewardship. }\end{array}$ & $\begin{array}{l}\text { Actively engaged in } \\
\text { study of the discipline } \\
\text { and seeks opportunities } \\
\text { to demonstrate and grow } \\
\text { the KSAs. } \\
\text { Developing the full } \\
\text { range of Bloom's } \\
\text { cognitive abilities, a } \\
\text { greater awareness of } \\
\text { their own limitations, } \\
\text { and a commitment to } \\
\text { professional and } \\
\text { disciplinary } \\
\text { stewardship. }\end{array}$ & $\begin{array}{l}\text { Demonstrates the KSAs } \\
\text { and commitments of a } \\
\text { steward of the } \\
\text { discipline, including } \\
\text { preserving disciplinary } \\
\text { integrity. } \\
\text { Is engaged in a } \\
\text { disciplinary or } \\
\text { professional community, } \\
\text { and seeks additional } \\
\text { opportunities to } \\
\text { reinforce less-well } \\
\text { developed skills. }\end{array}$ \\
\hline
\end{tabular}

These are important, general, descriptions of how you can recognize in yourself - and in others - the level of stewardship a person has reached. As you learn more about stewardship you will be able to both describe the "importance of disciplinary and professional stewardship" and document how this is demonstrated in your work (whether in school or the workplace). Your first objective should be to create or compile evidence that you are performing at the novice level on all KSAs. This may not happen all at the same time, and you might have evidence that you are performing at the apprentice level on some KSAs while you continue to grow towards that level on other KSAs. The point is,

While we are focused on your initiation of growth as a steward, you can also use these descriptions to help you identify ethical and stewardly collaborators, mentors, and workplaces. Rios et al. (2019) describe the development of the Mastery Rubric for Stewardship; here we focus on each KSA and how you can utilize the performance level descriptors to document the 
level at which you perform today, make plans to grow your performance level, and then demonstrate that growth.

Table 3. Stewardship KSA 1: Requisite Knowledge/Situational Awareness

\begin{tabular}{|l|l|l|}
\hline Novice & Apprentice & Journeyman \\
\hline $\begin{array}{l}\text { Largely unaware of the } \\
\text { professional community } \\
\text { and standards within }\end{array}$ & Learning to recognize when & Exercises professional practice \\
ahich their academic or & stewardship, that professional & standards and recognizes \\
professional interests & standations in which stewardship \\
operate. & both legal/illegal and & should be modeled and/or \\
applied with respect to \\
themselves and others, and to \\
ethical/unethical continua, and \\
how to recognize and respond \\
to these features. & $\begin{array}{l}\text { interactions within and outside } \\
\text { of the profession or discipline. }\end{array}$ \\
\hline
\end{tabular}

The first KSA comes "first" because it is essential to all the others. The content of this KSA is mainly professional standards in general- specific standards (American Statistical Association, 2018 and Association of Computational Machinery, 2018) are discussed more fully elsewhere (Tractenberg, 2019). However, applying Bloom's levels 1-3 to the professional practice standards will not be enough to understand when such guidelines are needed, or how to prioritize guideline principles in the events that more than one applies in any situation. Moreover, knowing and being able to use/prioritize the guidelines that outline ethical professional practice is necessary, but not sufficient, to being a steward. Instead, this describes the apprentice steward - and this can also describe the long-time practitioner who is new to the stewardship construct. To perform this KSA at the journeyman level requires in depth understanding of when and how to use the professional practice standards. Importantly, the journeyman is not acting stewardly for themselves alone, but also modeling this mindset for others - inside and outside the discipline.

Table 4. Stewardship KSA 2: Create and/or generate new methods/new knowledge

\begin{tabular}{|l|l|l|}
\hline Novice & Apprentice & Journeyman \\
\hline
\end{tabular}




\begin{tabular}{|c|c|c|}
\hline $\begin{array}{l}\text { Has limited awareness of } \\
\text { the knowledge and } \\
\text { activities of the discipline, } \\
\text { and limited exposure to } \\
\text { the ethical issues involved } \\
\text { in their creation and use. } \\
\text { Learning that } \\
\text { knowledge is generated; } \\
\text { and that the creation of } \\
\text { new methods or } \\
\text { knowledge may have } \\
\text { ramifications beyond the } \\
\text { original intent. }\end{array}$ & $\begin{array}{l}\text { Learning to create methods and } \\
\text { knowledge in a manner that } \\
\text { strengthens and advances the } \\
\text { field and disciplinary } \\
\text { community. } \\
\text { Developing the ability to } \\
\text { recognize when new methods } \\
\text { or knowledge can be used for } \\
\text { unethical ends, and how } \\
\text { stewards of the discipline } \\
\text { respond. } \\
\text { Learning how to balance a } \\
\text { commitment to strengthen and } \\
\text { advance the discipline with } \\
\text { advancing one's career }\end{array}$ & $\begin{array}{l}\text { Generates, and transparently } \\
\text { communicates, new methods } \\
\text { and knowledge to strengthen } \\
\text { and advance the field. } \\
\text { Considers how new ideas can } \\
\text { be used for unethical ends, and } \\
\text { models how to respond when } \\
\text { such action occurs. } \\
\text { Prioritizes the disciplinary } \\
\text { community over metrics that } \\
\text { devalue it. Challenges such } \\
\text { metrics whenever possible. }\end{array}$ \\
\hline
\end{tabular}

This KSA is clearly a direct reflection of data science practice, so the novice is still in the process of learning what "data science" is all about, and will have limited responsibility for making contributions to the field. However, rather than committing this new knowledge to memory, the novice steward of data science will also be internalizing the process by which knowledge is generated. Understanding that generating new methods, like the data scientist who created the technology that was exploited by Cambridge Analytica, must be balanced against your commitment to creating ethical methods, or methods that mitigate, rather than cause, harms, is essential to ethical practice as well as the development of stewardship. If that developer had achieved the apprentice level on this KSA, and recognized that their method could be used for unethical ends (as it was), perhaps he might have acted to prevent those unethical uses or notified the public that they were possible. The journeyman applies this level of stewardship to both their own and others' work.

Table 5. Stewardship KSA 3: Critically evaluate extant and emerging ideas

\begin{tabular}{|l|l|l|}
\hline Novice & Apprentice & Journeyman \\
\hline $\begin{array}{l}\text { Limited ability to evaluate } \\
\text { ideas or differentiate } \\
\text { between assertions and } \\
\text { arguments within the } \\
\text { discipline. }\end{array}$ & $\begin{array}{l}\text { Learning how professionals } \\
\text { review, critique, and challenge } \\
\text { each other's ideas and } \\
\text { arguments. }\end{array}$ & $\begin{array}{l}\text { Critically evaluates knowledge } \\
\text { and ideas within the discipline } \\
\text { or profession and the } \\
\text { paradigms by which this } \\
\text { knowledge is derived, and } \\
\text { promotes this evaluation by } \\
\text { others. }\end{array}$ \\
$\begin{array}{l}\text { Uncritically treats vetted } \\
\text { ideas and materials as } \\
\text { "true." }\end{array}$ & $\begin{array}{l}\text { Practicing these skills through } \\
\text { guided work with increasing } \\
\text { levels of disciplinary } \\
\text { engagement and independence. }\end{array}$ & $\begin{array}{l}\text { Participates in the vetting of } \\
\text { new and emerging ideas within } \\
\text { the profession or discipline. }\end{array}$ \\
\hline
\end{tabular}




\begin{tabular}{|l|l|l|}
\hline $\begin{array}{l}\text { together to form } \\
\text { arguments and evidence- } \\
\text { based reasoning. }\end{array}$ & $\begin{array}{l}\text { evaluate their work according } \\
\text { to disciplinary standards. }\end{array}$ & $\begin{array}{l}\text { Exhibits intellectual humility } \\
\text { and ensures their contributions } \\
\text { to the field are well-reasoned } \\
\text { and well-supported. }\end{array}$ \\
\hline
\end{tabular}

Much of our formal education is spent learning and remembering "extant ideas", or what constitutes "current knowledge" for the field in which we study. Not much time is spent critically evaluating such ideas during schooling, but this can be an important activity in the workplace. Learning how to be critical and constructive, if that is needed, is essential for team or group work, and is especially crucial for those in managerial, mentoring, or supervisory positions. In the workplace, there is rarely -if ever - one "right" answer (unlike every multiple-choice exam you have ever taken). Therefore, it is not surprising that the novice may be unprepared to critically evaluate either existing or emerging ideas. However, as an apprentice data scientist (and steward), you may be cultivating new and emerging ideas of your own, so it is important to be able to evaluate these in a critical and constructive way. Once these skills can be demonstrated for your own work, they can be applied to other work and ideas. Intellectual humility (https://en.wikipedia.org/wiki/Intellectual_humility) is the correct perception of your own knowledge in terms of its strengths and weaknesses. Understanding that "what you know" may actually be mistaken, and the "correct" perception means you can balance this knowledge with your abilities to discover additional evidence, so that your perception does not overwhelm you into a total inability to make any kind of decision at all (because you don't trust yourself). Your new and growing awareness of how well you exhibit the different abilities in Bloom's taxonomy is evidence of intellectual humility - but being able to justify your confidence in your, or others', ideas with rational arguments is an essential part of stewardship. The journeyman steward insists on well-reasoned and well-supported contributions to the field, and can critically and constructively evaluate such ideas. The apprentice must develop sufficient intellectual humility to do this, meaning that in the novice stage, you must develop the understanding that reasoning and evidence are key to effective arguments for the discipline. In order to eventually demonstrate journeyman level performance, this understanding as well as the abilities to deploy it must be developed.

Table 6. Stewardship KSA 4: Conserve ideas (or rejects ideas if non-conservation is justified)

\begin{tabular}{|l|l|l|}
\hline Novice & Apprentice & Journeyman \\
\hline $\begin{array}{l}\text { Entering the field by } \\
\text { learning about the } \\
\text { fundamental ideas, } \\
\text { thinkers, and } \\
\text { accomplishments of the } \\
\text { past. }\end{array}$ & $\begin{array}{l}\text { Learning to conserve } \\
\text { fundamental ideas of the field } \\
\text { through engagement, } \\
\text { application, relation, and } \\
\text { extension, as well as } \\
\text { qualification and critique. }\end{array}$ & $\begin{array}{l}\text { Critically conserves the ideas } \\
\text { that advance the field and } \\
\text { preserve its integrity. }\end{array}$ \\
$\begin{array}{l}\text { Attention is focused on } \\
\text { remembering and } \\
\text { understanding core } \\
\text { (highly conserved) ideas; } \\
\text { justifies neither their } \\
\text { conservation nor rejection }\end{array}$ & $\begin{array}{l}\text { Learning to recognize } \\
\text { processes by which ideas in the } \\
\text { field are vetted and that re- } \\
\text { evaluation and conservation } \\
\text { are essential to the integrity of } \\
\text { the field. }\end{array}$ & $\begin{array}{l}\text { and extra-disciplinary } \\
\text { influences, in describing and } \\
\text { justifying decisions of } \\
\text { conservation or non- } \\
\text { conservation of ideas, models, } \\
\text { and views. }\end{array}$ \\
\hline
\end{tabular}




\begin{tabular}{|l|l|l|}
\hline of ideas or arguments. & $\begin{array}{l}\text { Learning to describe and } \\
\text { justify decisions about } \\
\text { conservation or non- } \\
\text { conservation. }\end{array}$ & $\begin{array}{l}\text { Recognizes their role in } \\
\text { shaping the field/ profession } \\
\text { and its history. }\end{array}$ \\
$\begin{array}{l}\text { Learning how these decisions } \\
\text { have shaped the history of the } \\
\text { field and the ideas that } \\
\text { are/have been conserved. }\end{array}$ & \\
\hline
\end{tabular}

In some data science projects, particularly early in training or education, it can sometimes seem like "whatever was done before" must be retained (conserved) because it worked before. In other cases it can seem like whatever is to be done must be innovative - so early work must be rejected simply because "it has already been done". The ability to justify decisions to conserve or reject would be based on concrete criteria by the novice, and as the novice transitions to the apprentice stage, a better understanding of more abstract justifications will be possible (and should be developed). It is up to the journeyman steward to be critical of decisions to both conserve and reject - meaning that achieving this level of performance requires those high-level Bloom's cognitive abilities, to evaluate and judge. As discussed earlier, developing the abilities to evaluate and judge requires that the earlier abilities have been learned and can be/are practiced. The history of the field of data science, while not particularly long, is full of examples where decisions about conservation and rejection have been made by those in practice as well as outside forces. Tracing the Cambridge Analytica scandal is only one recent example of decisions to keep and deploy the technology that led or lead to harms to individuals who did not consent to have their data accessed; the leaders of this firm then decided to close that firm and start another one with the same technology - effectively conserving the idea that it is justified to unethically and in some contexts illegally obtaining other people's data. Clearly, those making such decisions have no interest in being stewardly; learning to recognize examples and individuals like this is essential to both your becoming a journeyman steward and also avoiding working with or for such nonstewards.

Table 7. Stewardship KSA 5: Responsibly write

\begin{tabular}{|c|c|c|}
\hline Novice & Apprentice & Journeyman \\
\hline $\begin{array}{l}\text { Learning disciplinary } \\
\text { writing standards with } \\
\text { attention to the details of } \\
\text { what must be recorded, } \\
\text { how to construct written } \\
\text { reports, and why } \\
\text { responsible writing } \\
\text { requires transparency. }\end{array}$ & $\begin{array}{l}\text { Gaining greater proficiency in } \\
\text { discipline-specific writing. } \\
\text { Demonstrating increased } \\
\text { sophistication in writing, } \\
\text { including content, rhetoric and } \\
\text { argumentation, and } \\
\text { transparency and professional } \\
\text { integrity. }\end{array}$ & $\begin{array}{l}\text { Independently writes in the } \\
\text { diversity of contexts and styles } \\
\text { specific to the field, to } \\
\text { generate, conserve, challenge, } \\
\text { and reject field-specific } \\
\text { knowledge and to engage } \\
\text { others in and outside the field. } \\
\text { Practices and promotes } \\
\text { transparency in their writing } \\
\text { for the sake of the discipline } \\
\text { and field. }\end{array}$ \\
\hline
\end{tabular}


Not every practitioner needs to write much, and in data science there might be more writing, across more contexts, in the formal education context than at work. However, all science- and most technical jobs - requires careful and thorough documentation. Thus, a novice data science steward may be learning both how to write "like a data scientist" and also why doing so in a responsible manner is an integral part of ethical practice. As we saw in the Cambridge Analytica example, if the data scientist that created the technology that was exploited to unethically access private Facebook data (from those who did not authorize its access) had transparently documented this potential application, maybe protections might have been created to prevent the harm that was done. The apprentice will undoubtedly have more opportunities for discipline-specific writing, and so will also be able to document their attention to transparency in their own and in others' writing. This KSA is likely to continue to develop well into the workplace, because writing for peer-practitioners can require extra care, so that transparency becomes automatic across multiple audiences (boss, peer, user, etc.). Moreover, in the workplace it will be essential to also be able to determine the level of transparency in other people's writing. If the data scientists at Cambridge Analytica had recognized that the developer of the technology they utilized had not written the documentation of his work with sufficient transparency, they may have pointed this out, identified the potential to do harm, and taken steps to correct it. Performing this KSA at the journeyman level is essential to ethical practice as well as to promoting the integrity of the field: clearly and transparently communicating both the technical details, and potential uses/misuses of the technology can only serve to raise awareness and can also serve to prevent harms that might otherwise be unintended, yet very real.

Table 8. Stewardship KSA 6: Responsibly teach/mentor/model

\begin{tabular}{|l|l|l|}
\hline Novice & Apprentice & Journeyman \\
\hline $\begin{array}{l}\text { As someone } \\
\text { uninitiated in the } \\
\text { field, the Novice } \\
\text { does not } \\
\text { undertake } \\
\text { teaching or } \\
\text { mentoring roles. }\end{array}$ & $\begin{array}{l}\text { Growing in disciplinary knowledge, } \\
\text { skills, and abilities and the ability to } \\
\text { pass these on to others. }\end{array}$ & $\begin{array}{l}\text { Possess the knowledge, skills, } \\
\text { and abilities of the discipline } \\
\text { and is able to pass these along } \\
\text { to others. } \\
\text { importance of competent mentoring } \\
\text { and modeling inherent in professional } \\
\text { practice and disciplinary } \\
\text { responsibilities. }\end{array}$ \\
$\begin{array}{l}\text { Seeks opportunities to learn about } \\
\text { workplace appropriate teaching and } \\
\text { learning, and to practice teaching, with } \\
\text { supervision if available. }\end{array}$ & $\begin{array}{l}\text { Teaches, mentors, and models } \\
\text { professionalism and the } \\
\text { commitments of stewardship in } \\
\text { both formal and informal } \\
\text { settings, within and outside the } \\
\text { field. }\end{array}$ \\
\hline
\end{tabular}

The novice is does not tend to have teaching or mentoring roles when they are early in their careers, but as noted earlier, the developmental stages are not time-dependent. It is important to recognize that a long-time practitioner who is unaware of stewardship will also not be able to teach or mentor with respect to stewardship in the field. However, in order to "be the change" (misquoting Ghandi again), or to promote and model stewardship, it is important to recognize and accept that your own commitment to ethical and stewardly practice sends signals 
to others- effectively, if implicitly, teaching. The apprentice is beginning to understand what actually constitutes a visible (and thereby, teachable) commitment to stewardship. In peer-topeer teaching (e.g., of new methods or methods that you developed), a focus on the responsibility to use the new technique/technology responsibly could be evidence of apprentice level performance on this KSA. Because stewardship is not commonly integrated into formal education, you may not observe a commitment to responsible use of data science KSAs in your instructors. The apprentice recognizes this and also seeks new opportunities where this commitment is available and prioritized. Once you begin to recognize such opportunities and document their importance for your own professional identity development, you will be better able to demonstrate that you perform this KSA at the journeyman level. Keep in mind how important it is that the KSA must be demonstrated at the stage you target in an observable way: you must be able to recognize this, and that will in turn facilitate your documentation that you perform this KSA at that level for others who will seek opportunities to develop stewardly habits with you.

Table 9. Stewardship KSA 7: Responsibly apply disciplinary knowledge

\begin{tabular}{|l|l|l|}
\hline Novice & Apprentice & Journeyman \\
\hline $\begin{array}{l}\text { As someone inexperienced } \\
\text { in the KSAs of the field, } \\
\text { the Novice is not expected } \\
\text { to apply them but is } \\
\text { learning that application } \\
\text { entails responsibilities for } \\
\text { the practitioner. }\end{array}$ & $\begin{array}{l}\text { Learning how and when to apply the } \\
\text { KSAs of the discipline and how } \\
\text { application entails professional and } \\
\text { ethical responsibilities, including } \\
\text { integrity, transparency, and respect. }\end{array}$ & $\begin{array}{l}\text { Applies the KSAs in a } \\
\text { way that preserves and } \\
\text { advances the field by } \\
\text { demonstrating integrity, } \\
\text { transparency, and respect } \\
\text { in interactions within and } \\
\text { outside of the profession } \\
\text { or discipline. }\end{array}$ \\
\hline
\end{tabular}

The novice is still learning the KSAs of their specific field, so would not have many opportunities to apply their disciplinary knowledge - yet. However, consideration of cases like the Cambridge Analytica example discussed earlier does demonstrate that you are becoming aware of that - and how - applying data science KSAs as you (learn to) practice entails responsibilities. These were not considered in the Cambridge Analytica example, and there are undoubtedly many more such examples currently (and will be in the future). Each time you are tasked with the application of new data science-specific knowledge-for example, as homework or final projects, you might also generate a brief "analysis" of what responsibilities this application creates for you. The apprentice is consolidating such experience and also actively seeking new opportunities to deepen their knowledge of their responsibilities. Taking an extra course on ethics would be an example of this, but it is the demonstration of your growth as a steward, not simply additional items on your transcript, that constitute evidence of apprenticelevel performance on this KSA. This might be one of the most important KSAs to demonstrate as you apply for jobs - that you perform this KSA at the journeyman level but also that you are committed to the integrity of the field as well as your own ethical practice. This type of evidence could easily distinguish such an applicant from among all those that would be considered: if an organization does not value (or, as might have been true for Cambridge Analytica, seeks to avoid employing those who promote) stewardship, then you definitely need to carefully consider such 
an environment. However, if the organization does value stewardship, or would appreciate the opportunity to pursue it, journeyman performance on this KSA will be highly valuable.

Table 10. Stewardship KSA 8: Responsibly communicate

\begin{tabular}{|c|c|c|}
\hline Novice & Apprentice & Journeyman \\
\hline $\begin{array}{l}\text { Discovering the rules for } \\
\text { communicating in the } \\
\text { discipline or profession. } \\
\text { Learning that stewards of } \\
\text { the discipline have a } \\
\text { responsibility to represent } \\
\text { their field to others in a } \\
\text { way that promotes the } \\
\text { integrity, transparency, and } \\
\text { respect of their profession. }\end{array}$ & $\begin{array}{l}\text { Learning how and when to } \\
\text { communicate with insiders and } \\
\text { outsiders about their discipline or } \\
\text { profession. } \\
\text { Recognizes that communicating as } \\
\text { a steward imparts responsibilities } \\
\text { that include demonstrating } \\
\text { integrity, transparency, and respect, } \\
\text { and seeks to exhibit their } \\
\text { commitment to these } \\
\text { responsibilities. }\end{array}$ & $\begin{array}{l}\text { Clearly and effectively } \\
\text { communicates the ideas, } \\
\text { perspectives, and content } \\
\text { of the discipline to } \\
\text { insiders and outsiders in a } \\
\text { way that promotes } \\
\text { integrity, transparency, } \\
\text { and respect. }\end{array}$ \\
\hline
\end{tabular}

The novice is discovering rules and is mainly concerned with concrete and objective features of communication, while the apprentice is beginning to engage with more abstract features of what it means to "communicate responsibly". As you compile evidence of your novice-level performance, you would focus on rules and possibly, laws that you follow. Once you have demonstrated the novice level performance, you can seek out more abstract features (seeking itself is part of the apprentice level performance) to learn and to demonstrate. If you are able to compile evidence at both levels by the time your pre-professional preparation is completed, you should then be able to begin compiling evidence of your clear and effective responsible - communication in the workplace, to demonstrate that you perform this KSA at the journeyman level.

\section{Conclusion.}

"... ethics is not a vaccine that can be administered in one dose and have long-lasting effects no matter how often, or in what conditions, the subject is exposed the disease agent. Teaching individual students and postdoctoral fellows good professional practices cannot be highly and widely efficacious until academic culture and society also model and reward ethical behaviour."

(National Academy of Engineering, 2009: 34; emphasis added)

Whether early in training or well into practice, orientation towards stewardship can be accomplished and built upon. Culture change towards stewardship is needed - and has to start somewhere. The stewardship model promotes ethical practice, but does so in an ongoing way one that explicitly avoids the current problem many disciplines face: how to "teach ethics" in a way that does not assume, as the National Academy of Engineering identifies as an incorrect assumption, that a one-time ethics course will suffice to prepare practitioners for their whole career. Stewardship is an active, purposeful mindset, so requires time to learn, as well as to grow. Each practitioner, manager, and instructor can be the change, become a steward, promote, 
discuss, and reward this mindset, and embrace/model/promote stewardship and integrity in the profession. The National Academy of Engineering report (2009) echoes Ghandi and is reiterated, in part, by Loukides: culture change is needed and it must promote ("model") and reward ethical behavior.

In the discussion of evidence that you perform each KSA at any level, we have touched on the possibility of convincing a potential employer of your achievements. This is an essential part of your evidence: you do not need to simply compile any evidence, but it should be specific and supportive of your claim that you do in fact perform that KSA at the target level. Evaluating your evidence from the perspective of someone who does not know you, someone you need to convince, is a crucial part of leveraging your stewardship evidence in your professional life.

Introducing the idea of stewardship into our conversations with our peers, supervisors, and collaborators, can help create the culture change - and encourage ongoing conversations that is essential to more ethical practice of statistics and data science worldwide and across contexts like academia, government, and business/industry. This article is intended to help you begin your evolution from novice steward to journeyman, so that you can follow Ghandi's (1913) suggestion: to " ...change ourselves, (so that) the tendencies in the world would also change."

Employers, managers, supervisors, mentors, and instructors should be stewards of their field, encouraging employees, team members, mentees, and students to join them in embodying and promoting this mindset. Hiring and promotion criteria may not currently include evidence of stewardly behaviors (and opportunities to create this evidence), but this is one "tendency in the world" that could be changed if new practitioners lead the way. New practitioners can also bring this mindset to their work in observable - shareable and therefore, culture-changing - ways. Applicants for data science positions may distinguish themselves from others with evidence of their commitment to their own professional integrity and to the integrity of the field. Applicants can also utilize "commitment to ethical practice" and "entrustable with the integrity of the field" as indicators that a potential workplace is going to promote or hinder their own development and demonstration of stewardship. 
References

American Statistical Association (ASA) ASA Ethical Guidelines for Statistical Practice-revised (2018) downloaded from https://www.amstat.org/ASA/Your-Career/Ethical-Guidelines-forStatistical-Practice.aspx on 30 April 2018.

Association for Computing Machinery (ACM). Code of Ethics (2018) downloaded from https://www.acm.org/about-acm/code-of-ethics on 12 October 2018.

BS Bloom (Ed.), with Engelhart MD, Furst EJ, Hill WH \& Krathwohl DR. (1956). Taxonomy of educational objectives: Handbook I: Cognitive domain. New York, NY: David McKay.

Golde CM, \& Walker GE. (Eds.). (2006). Envisioning the future of doctoral education:

Preparing stewards of the discipline-Carnegie essays on the doctorate. San Francisco: Jossey-

Bass.

Ghandi, MK. (1913). (MK Ghandi, 1913) General Knowledge About Health; VOL 13, Ch 153, Page 241. Printed in the Indian Opinion on 9/8/1913 From The Collected Works of M.K.Gandhi; published by The Publications Division, New Delhi, India.

Loukides M, Mason H, Patil DJ. (10 July 2018). Doing good data science. Downloaded from https://www.oreilly.com/ideas/doing-good-data-science on 15 July 2018

National Academy of Engineering and National Research Council. (2009). Ethics education and scientific and engineering research: what's been learned? What should be done? Summary of a workshop. Washington, DC: The National Academies Press. Downloaded from http://www.nap.edu/catalog/12695.html on 20 Dec 2013.

Rios CR, Golde CM, Tractenberg RE. (2019). The preparation of stewards with the Mastery Rubric for Stewardship: Re-envisioning the formation of scholars and practitioners. https://osf.io/preprints/socarxiv/vw7j5/

Simonite T. (2018). Should data scientists adhere to a Hippocratic Oath? Accessed from https://www.wired.com/story/should-data-scientists-adhere-to-a-hippocratic-oath/

Techworld. (2019). The most infamous data breaches. 12 March 2019. Accessed from https://www.techworld.com/security/uks-most-infamous-data-breaches-3604586/ on 25 March 2019.

Tractenberg RE, Russell AL, Morgan G, FitzGerald KT, Collmann J, Vinsel L, Steinmann M, Dolling LM. (2015) Amplifying the reach and resonance of ethical codes of conduct through ethical reasoning: preparation of Big Data users for professional practice. Science and Engineering Ethics 21(6): 1485-1507. DOI 10.1007/s11948-014-9613-1

Tractenberg, RE. (2017). Preprint. The Mastery Rubric: A tool for curriculum development and evaluation in higher, graduate/post-graduate, and professional education. Published in the Open Archive of the Social Sciences (SocArXiv), osf.io/preprints/socarxiv/qd2ae

Tractenberg RE. (2019). Preprint. Strengthening your practice and your profession using ethical guidelines. Published in the Open Archive of the Social Sciences (SocArXiv), DOI in progress. Wong, Julia Carrie (2019-03-22). "Facebook acknowledges concerns over Cambridge Analytica emerged earlier than reported". The Guardian. Retrieved online 2019-03-25. 